\title{
पंजाबी गायकी का बदलता स्वरूप
}

\section{Dr.Amanpreet Kaur Kang}

Assistant Professor, Department of Music, G.G.S Khalsa College for Women, Jhar Sahib, Ludhiana, Punjab

पंजाबियों का जीवन शुरू से ही संघर्षमय रहा है। इस प्रान्त की भौगोलिक स्थिति ऐसी रही है कि भारत का प्रवेश द्वार होने के कारण यहां के लोगों को सदियों से बाहर से आने वाले आक्रमणकारियों से टक्कर लेनी पड़ी है। यही कारण है कि पंजाबी लोक-गायक आज तक भी बहादुरी के किस्से / गीत / वारें आदि सुना कर के यहां के लोगों के जोशीले स्वभाव से सम्बन्धित रूचियों को तृत्प करते रहते हैं।यहां की जागीरदारी प्रथा के कारण कठोर सामाजिक नियमों ने व्यक्तिगत स्वतंत्रता का गला घोंट कर रखा। परिणाम स्वरूप यहां हीर-रांझा, मिर्ज़ा-साहिबां, सोहणी-महींवाल जैसे प्रेम-प्रसंगों ने पारम्परिक पंजाबी लोक-गायकी को शिखर तक पहुंचा दिया।

समय के साथ परिवर्तन आया। वैज्ञानिक/औद्योगिक उन्नति हुई। आज यातायात के उन्नत साधनों, प्रिंट मीडिया, शिक्षा एवं इलैक्ट्रोनिक मीडिया में हुई उन्नति ने इस नई सामाजिक व्यवस्था को पूरी तरह से नया रूप दे दिया है। यद्यपि सब कुछ तो नहीं बदला परन्तु इस हद तक परिवर्तन ज़रूर आ गया है कि नई व्यवस्था ने पारम्परिक लोक-गीतों और इनकी प्रस्तुति को पहले जैसा नहीं रहने दिया। नये-नये गीत लिखे जा रहे हैं। अब इस तरह से परिवर्तित लोक-गायकी को वर्तमान लोक-गायकी का नाम दिया जा चुका है।

लोक-गीत सामाजिक परिवेश में से जन्म लेता है। इस लिए उसके बोल स्वभाविक रूप से जन-साधारण की भावनाओं को व्यक्त करने वाले होते हैं। परन्तु वर्तमान पंजाबी गायकी साहित्य, प्रिंट मीडिया एवं इलैक्ट्रोनिक मीडिया के माध्यम से पश्चिमी सभ्यता/संस्कृति से इस तरह से प्रभावित हुई है कि यह गायकी जन-साधारण के वास्तविक जीवन से दूर चली गई है। कभी-कभी कोई गायक आज लोगों के जीवन की वास्तविकता को व्यक्त करने वाले बोलों का प्रयोग अपनी गायकी में करता है। आम तौर पर प्रेम-प्रसंग को लेकर ही गीतों का गायन किया जाता है। ऐसे गीतों में भी काम-भावना को ही प्रेम का नाम देकर केवल 
पुरूष-स्त्री के सम्बन्ध की बात की जाती है। इस की अपेक्षा पारम्परिक गीतों में माँ-पुत्र, माँ-बेटी, भाई-भाई, भाई-बहन एवं पति-पत्नी आदि रिश्तों का चित्रण इनकी पवित्रता सहित किया जाता था। वर्तमान गायकों के गीतों में से यद्यपि सभी गीतों के बोलों में तथा कथित प्रेम की बात नहीं होती। बहुत से गायक जैसे गुरदास मान, हरभजन मान, लखविन्दर वडाली, कंठ कलेर, सरबजीत चीमा, सतिन्दर सरताज, हरजीत हरमन, मलकीत सिंह, मनप्रीत अख़तर, मनमोहन वारिस, बलकार सिद्धू, जसपिन्दर नरूला, राणी रणदीप आदि सामाजिक सरोकारों वाले गीत भी गाते हैं परन्तु कुछ गायक, विशेष कर नए गायक आजकल आम तौर पर अपने गीतों में लड़की (कुड़ी) के बारे में कामुक अंदाज़ में ही बात करते हैं। इस प्रकार के गीतों को गाने वाले कलाकारों के कारण वर्तमान लोक-गायकी की पहचान ही अश्लील गायकी के रूप में स्थापित होती जा रही है। यद्वपि पारम्परिक गायकों में से अधिकतर गायक गायन प्रस्तुत करते समय सदाचारिकता का दामन नहीं छोड़ते थे। वह अश्लील मुद्राएं नहीं बनाते थे।

वर्तमान गायकी की प्रस्तुति में साज़ों, विशेष रूप से ड्रम, की आवाज़ इतनी ऊँची होती है कि गूँज के साथ मिलकर गायक की आवाज़ को बीच में ही डुबो देती है। कुल मिला कर जो सुनने को मिलता है वह शोर-शराबे से कम नहीं होता, खासतौर पर शादी या किसी पार्टी के अवसर पर। कई बार सुर की कमी को छुपाने के लिए भी ऐसा किया जाता है। वाद्यो के प्रयोग के बारे में प्रसिद्ध पारम्परिक गायक गुरपाल सिंह पाल का कथन है, हमारे समय में साज़ बहुत कम बजाए जाते थे। आवाज़ एवं गीत के बोलों को स्पष्ट सुनाने की कोशिश होती थी। साज़ तो बीच में गायक को विश्राम देने के लिये ही बजाए जाते थे। अब तो साज़ बहुत ऊँची आवाज़ में बजाए जाते हैं। गीत के बोल समझ में नही आते। अब तो साज़ों को विश्राम देने के लिए गाया जाता है। साज़ गायक की आवाज़ से ऊँचे बजते हैं।

बोलों को सुर एवं ताल के माध्यम से मंच पर लाने की प्रक्रिया को ही प्रस्तुति कहा जाता है जिसके लिए साज़ों की ज़रूरत होती है। पारम्परिक लोक-गायकी की एक अहम विशेषता यह थी कि इसमें लोक-गायक आमतौर पर स्वयं भी साज़ बजाते थे। लोक-गायकी की विभिन्न प्रणालियों में भिन्न-भिन्न वाद्यों के वादन की परम्परा थी। यहां तक कि पारम्परिक गायकों की गायन प्रणाली का नामकरण अधिकतर उनके साज़ों के नामे पर ही आधारित था जैसे ढाडी, तूम्बे- तारे या तूम्बे 
अलगोज़े वाले गायक आदि। दीदार सिंह रटैण्डा, यमला जट्ट, जगत सिंह जग्गा, करनैल सिंह पारस, सोहण सिंह सीतल, गुरपाल सिंह पाल, मुहम्मद सद्दीक, देस राज लचकाणी, ईदू शरीफ़, सुरिन्द्र छिन्दा, कुलदीप माणक आदि लगभग सभी पारम्परिक पुरूष गायक खुद साज़ बजाते रहे हैं। परन्तु वर्तमान गायकों मे से कुछ एक गायकों को छोड कर बाकी लगभग सभी लोक-गायक ऐसे है जो खुद कोई भी साज़ नहीं बजाते।

आज के पूंजीवादी समाज मे हर एक व्यक्ति पैसा कमाने की दौड़ में शामिल हो चुका है। इस मामले में वर्तमान गायक भी पीछे नहीं है। उनके लिए गीत लिखने वाले गीतकार भी ऐसे गीत लिख रहें हैं। जिन्हें वह गायकी की मण्डी में बेच कर अधिक से अधिक धन कमा सकें। संगीत निर्देशक एव रिकार्डिंग कम्पनियां भी अधिक से अधिक धन कमाने के लिये, जो कोई भी पैसा ले आता है उस की एल्बम् निकाल देते हैं। उस समय वह ये नहीं देखते कि गीत रिकार्ड करने योग्य है या नहीं। सामाजिक दृष्टि से उसकी कोई उपयोगिता है या नहीं। एक तरफ तो श्रोताओं की मनोभावना को मुख्य रखते हुये गायन करते हैं और दूसरी तरफ वह संगीतकारों, के रिकार्डिंग कम्पनियों के, और अपने अधिक से अधिक पैसा कमाने की इच्दा से प्रेरित हितों की पूर्ति को ध्यान में रखकर जन-मानसिकता को ढाल कर उसका फायदा भी लेते हैं। ऐसा करते समय वह सामाजिक यथार्थ को एक तरफ कर देते हैं। सामाजिक/नैतिक/धार्मिक मूल्यों को दरकिनार करते हैं। बिलकुल वैसे ही जैसे अंग्रेजों ने भारत में आकर भारतीयों को पहले तो मुफ्त में ाय पिलाई और जब वह लोगों को पीने में अच्छी लगने लगी तो बेचनी शुरू कर दी। इस प्रकार उन्होंने चाय को लोगों की पसन्द बना दिया।

वर्तमान गायक भी मंच पर लड़कियों को अपने साथ छोटे कपड़ों में नचा कर श्रोताओं की कामुक प्रवृत्तियों को उत्तेजित करते हैं और फिर अश्लील गायकी को जायज़ ठहराने के लिये कहते हैं कि यह श्रोतागण की इच्छा है। अब तो जब श्रोता ऐसा बन गया है तो उसके लिये, नचाने वाली बीट वाली गायकी को पसन्द करना स्वाभविक हो गया है। अब तो बहुम कम श्रोता ऐसे है जो अच्छे संगीत वाली गायकी पसन्द करते हैं। अधिकतर जवान लड़के-लड़कियां पाश्चात्य संस्कृति के रंग में रंग दिये गए हैं जो पारम्परिक लोक-गायकी को गायकी ही नहीं मानते। 
पारम्परिक गायकी से वर्तमान गायकी तक आते-आते पंजाबी लोक-गायकी का स्तर बहुत नीचे आ गया है। अगर सावधान होकर चला जाए तो स्थिति इतनी निराशाजनक भी दिखाई नहीं पड़ती क्योंकि आज के अच्छे गायकों की संख्या भी काफी है यद्यपि यह गायक बहुसंख्या में नहीं है। यहीं संख्या बहुसंख्या में भी परिवर्तित हो सकती है अगर विद्यालयों, महाविद्यालयों व विश्वविद्यालयों में आयोजित मेलों / प्रतियोगिताओं में लोक-गायकी की प्रस्तुति को महत्त्व देते हुये छात्रों के मनों में पारम्परिक गायकी एवं अच्छी वर्तमान लोक-गायकी के प्रति रूचि को बढ़ावा दिया जाए। प्रिंट मीडिया एवं इलैक्ट्रानिक मीडिया का दायित्व सुनिश्चित करने के लिए ऐसा सेंसर बोर्ड कायम करना चाहिए जो सही अर्थों में अपना कार्य करे। अगर बोल पक्ष या इसकी प्रस्तुति का स्तर गिरने लगे तो सैंसर बोर्ड ऐसी गायकी को मेंच/रेडियो/टेलिविज़न पर आने से रोके। इस सम्बन्ध में कानून की व्यवस्था भी की जा सकती है। जिसके अनुसर निर्धारित नियमों का उल्लघंन करने वाले गायक/गीतकार/निर्देशक/रिकार्डिंग कम्पनी को सज़ा भी सुनाई जा सके।

यदि इन सुझावों पर अमल किया जाए तो उम्मीद की जा सकती है कि अच्छा निर्देशन न देने वाले संगीतकार एवं अच्छे गीतों की रिकार्डिंग न करने वाली कम्पनियां आदि सभी इस क्षेत्र में नकारात्मक भूमिका अदा करने वाले, पंजाबी लोक-गायकी के स्तर को गिरा नहीं सकेंगें।

1 डॉ. दर्शन सिंह नरूला, पंजाब दा संगीत : विरसा ते विकास, पृष्ठ-49

2 डॉ. अजमेर सिंह, कली छनद : निकास ते विकासश, पृष्ठ-190

3 डॉ. गुरनाम सिंह, पंजाबी लोक संगीत विरासत (भाग पहला), पृष्ठ-11 